\title{
Anatomical and visual outcome of retinal detachment surgery in children
}

\author{
T K H Butler, A W Kiel, G M Orr
}

\begin{abstract}
Aims-To evaluate the visual and anatomical outcome, as well as complications following surgery, for rhegmatogenous retinal detachment in children at a tertiary referral centre over a 5 year period. Methods-A retrospective survey of all children (aged 0-16 years) who underwent primary retinal detachment surgery at Queen's Medical Centre between April 1994 and March 1999.

Results-15 consecutive patients were identified with a mean follow up of 14.7 months (range 3-57) and a mean age of 12.4 years. Trauma was the cause in $40 \%$ (6/15). Complete retinal reattachment was achieved in $86.6 \%(13 / 15)$. Visual improvement occurred in $53.3 \%(8 / 15)$, worsening of vision occurred in $13.3 \%(2 / 15)$, with no change in the remaining $33.3 \%(5 / 15)$. Visual acuity was $D$ 6/12 in $6.6 \%(1 / 15)$ preoperatively, and $26.6 \%$ (4/15) postoperatively.

Conclusions-Retinal detachment in children is rare compared with adults. There are therefore limited data available for this group of patients. These data provide one unit's experience over a 5 year period, and may help provide a basis for information for patients and their parents when discussing the risks and potential benefits of surgery for retinal detachment in the paediatric population.

(Br f Ophthalmol 2001;85:1437-1439)
\end{abstract}

Children comprise a small fraction of the total number of patients treated for rhegmatogenous retinal detachment (RRD). Hence the available data for this group of patients are limited, and there are very few large series in the published literature. Winslow et $a l^{1}$ reported a series of 109 patients aged $0-16$ years over an 8 year period, in which they found juvenile RRD to account for $2.9 \%$ of all detachments. In this series juvenile RRD was most frequently associated with trauma (44\%), myopia (15\%), aphakia $(10 \%)$, and retinopathy of prematurity $(8 \%)$. This study was done in the previtrectomy era, and so all these patients had scleral buckling surgery. Successful retinal reattachment was achieved in $80 \%$, with vision of $20 / 100$ or better in $22 \%$ preoperatively and $58 \%$ postoperatively.

Studies of juvenile RRD in more recent literature have tended to focus on the treatment of complex RRD with pars plana vitrectomy and silicone oil, ${ }^{2-5}$ those associated with retinopathy of prematurity, ${ }^{67}$ or scleral buckling surgery in uncomplicated juvenile retinal detachment without proliferative vitreoretinopathy (PVR), ${ }^{8}$ but there is a paucity of recent published audit of primary $\mathrm{RRD}$ repair in the general paediatric population.

There are more data available in the literature regarding RRD surgery in the adult population. Sullivan et al ${ }^{9}$ reported a UK series of 153 adult patients in which the retinal reattachment rate was also $80 \%$, with $47 \%$ achieving $6 / 12$ vision or better at 6 months. However, the pathogenesis behind RRD in children often differs substantially from that seen in adults, and hence extrapolation of data obtained from the adult population may not be appropriate.

It was our aim to identify those children who underwent surgery for RRD at Queen's Medical Centre over a 5 year period, to evaluate their visual and anatomical outcome, and complications following surgery.

\section{Patients and methods}

All children, aged $0-16$ years, who had undergone surgery for RRD at Queen's Medical Centre between April 1994 and March 1999 were identified from the database of operating codes given to all patients at the time of surgery. Case notes for these patients were then retrieved and the data collected on a standardised form. The data set included details of age; sex; total follow up; method of referral; refraction; local and systemic aetiological factors; duration of detachment; macula status; type, site, and number of breaks; extent of subretinal fluid; presence of proliferative vitreoretinopathy (PVR); type of primary and any subsequent surgical procedure and the time interval between. Outcome measures included visual acuity, anatomical success, and the number of reoperations. Anatomical success was defined as persisting retinal reattachment at last follow up (at least 3 months postoperatively) in the absence of silicone oil.

\section{Results}

PATIENT CHARACTERISTICS

There were 864 cases of RRD repair carried out between April 1994 and March 1999. Of these, $15(1.7 \%)$ were in children aged between $0-16$ years. The mean age was 12.4 years (range $9-15)$. Nine $(60 \%)$ were male, six $(40 \%)$ female, with eight (53\%) right eyes and seven $(47 \%)$ left eyes. The mean length of follow up was 14.7 months (range 3-57). The refractive status of the group was within 2.50 DS of emmetropia in $11(73 \%)$, a spherical equivalent of more than $-6.00 \mathrm{DS}$ in three $(20 \%)$, and one $(6 \%)$ aphakic patient.

A contributing aetiological factor was present in $12(80 \%)$ of the cases. These are shown in Table 1 . Three (20\%) patients had no 
Table 1 Contributing aetiological factors, and methods of presentation

\begin{tabular}{llll}
\hline Case No & Age at presentation & Aetiological factors & Method of presentation \\
\hline 1 & 9 & None & Incidental finding \\
2 & 12 & None & Incidental finding \\
3 & 13 & Low myopia & Incidental finding \\
4 & 15 & High myopia & Incidental finding \\
5 & 14 & Trauma & Following trauma \\
6 & 12 & Trauma & Following trauma \\
7 & 9 & Pseudophakia, high myopia & Incidental finding \\
8 & 14 & Trauma & Following trauma \\
9 & 13 & Trauma & Other self referral \\
10 & 13 & Trauma & Following trauma \\
11 & 14 & None & Following trauma \\
12 & 11 & Buphthalmos (Sturge-Weber) & Other self referral \\
13 & 11 & Trauma & Incidental finding \\
14 & 12 & High myopia, ${ }^{\star}$ ROP & Other self referral \\
15 & 14 & & \\
Mean & 12.4 & & \\
\hline
\end{tabular}

${ }^{\star}$ Myopia $>6 \mathrm{D}$

aetiological factors. These presented after routine eye tests had identified unilateral poor vision. All three had inferior dialyses.

The methods by which the patients presented are summarised in Table 1 . Seven patients $(47 \%)$ presented as an incidental finding. Among this group, visual acuity ranged from $6 / 9$ to $3 / 60$ in the affected eye, but all had vision of $6 / 9$ or better in the unaffected eye.

CHARACTERISTICS OF RETINAL DETACHMENT

The duration of RRD, where known, ranged from 2 days to 12 months, with a mean of 3 months. The different types and anatomical distribution of the various pathologies are shown in Table 2. Five patients (33\%) had dialyses and three patients $(20 \%)$ had posterior retinal breaks (10 $\mathrm{mm}$ or more behind the ora serrata).

\section{SURGICAL PROCEDURES FOR RRD}

Only three $(20 \%)$ patients had primary vitrectomy for RRD, these had multiple (cases 5 and 8 ) or large (case 10) posterior holes. The remaining $12(80 \%)$ had a conventional external approach, with subretinal fluid (SRF) drainage in $8 / 12(67 \%)$, and gas injection in $4 / 12(33 \%)$. The details are shown in Table 2.

\section{OUTCOME AND COMPLICATIONS}

Anatomical success with complete retinal reattachment was achieved in 13/15 (86.6\%). The visual outcomes are shown in Table 2 . Visual acuity was at least $6 / 12$ or better in $1 / 15(6.6 \%)$ preoperatively, and $4 / 15(26.6 \%)$ postoperatively. Visual improvement occurred in $8 / 15$ $(53.3 \%)$, remained unchanged in $5 / 15$ $(33.3 \%)$, and vision worsened in $2 / 15(13.3 \%)$. Of the two cases who had worsening of vision, one had macular scarring (case 1), the other had PVR and redetachment (case 15).

Four patients had poor preoperative visual acuity despite the macula remaining attached. Case 5 had macula commotio retinae and developed subsequent macula scarring. Case 7 had pre-existing amblyopia. Cases 8 and 10 had co-existent macular holes.

Two patients were registered blind. Case 9 had had congenital cataracts extracted and subsequent aphakic glaucoma. Case 15, born at 27 weeks of gestation, had burnt out retinopathy of prematurity, myopia, and ultimately bilateral inoperable RRD with PVR. Cases 4, 7, and 9 had pre-existing amblyopia which limited their postoperative visual acuity.

There were no recorded intraoperative complications. The overall postoperative complication rate was 5/15 (33\%). Three patients $(20 \%)$ required reoperations for redetachment, all three had PVR (cases 10, 12, 15). Macula scarring occurred in three $(20 \%)$ patients (cases $1,5,10$ ), and cataract developed in one $(6.7 \%)$ patient (case 15$)$.

\section{Discussion}

Rhegmatogenous retinal detachment is a relatively rare condition in children, hence the paucity of large series on this patient group. Of

Table 2 Summary of retinal detachment characteristics, surgical approach, preoperative and postoperative visual acuity

\begin{tabular}{|c|c|c|c|c|c|c|c|c|c|c|}
\hline \multirow[b]{2}{*}{$\begin{array}{l}\text { Case } \\
\text { No }\end{array}$} & \multirow[b]{2}{*}{$\begin{array}{l}\text { Duration of } \\
R D \text { (months) }\end{array}$} & \multirow[b]{2}{*}{$\begin{array}{l}\text { Macula } \\
\text { status }\end{array}$} & \multirow{2}{*}{$\begin{array}{l}\text { Extent } \\
\text { (clock } \\
\text { hours) }\end{array}$} & \multirow[b]{2}{*}{ Type of break } & \multirow[b]{2}{*}{$\begin{array}{l}\text { No of } \\
\text { breaks }\end{array}$} & \multirow[b]{2}{*}{$\begin{array}{l}\text { Site of } \\
\text { breaks }\end{array}$} & \multirow[b]{2}{*}{$\begin{array}{l}\text { Primary procedure subsequent surgery } \\
\text { (interval in months) }\end{array}$} & \multicolumn{2}{|l|}{ Visual acuity } & \multirow[b]{2}{*}{ 2nd eye } \\
\hline & & & & & & & & $\begin{array}{l}\text { At } \\
\text { presentation }\end{array}$ & At last f/up & \\
\hline 1 & Not known & Off & 5 & Dialysis & 1 & $\mathrm{I} / \mathrm{T}$ & Drain/cryo/buckle & $6 / 36$ & $6 / 60$ & $6 / 5$ \\
\hline 2 & Not known & Off & 6 & Dialysis & 1 & $\mathrm{I} / \mathrm{T}$ & Drain/cryo/buckle & $6 / 60$ & $6 / 60$ & $6 / 5$ \\
\hline 3 & Not known & On & 2 & Peripheral holes & 2 & $\mathrm{I} / \mathrm{T}$ & Cryo/buckle/paracentesis & $6 / 9$ & $6 / 9$ & $6 / 6$ \\
\hline 4 & Not known & Off & 6 & Small horseshoe & 1 & $\mathrm{~T}$ & Drain/cryo/buckle & $3 / 60$ & $2 / 60$ & $6 / 5$ \\
\hline 5 & 0.25 & On & 2 & $\begin{array}{l}\text { Holes in necrotic } \\
\text { retina }\end{array}$ & 4 & $\mathrm{~S} / \mathrm{T} / \mathrm{post}$ & Vitrectomy/cryo/gas & $6 / 36$ & $6 / 18$ & $6 / 5$ \\
\hline 6 & 0.25 & Off & 3 & Multiple small holes & $10+$ & $\mathrm{S} / \mathrm{T}$ & Cryo/buckle & $6 / 18$ & $6 / 9$ & $6 / 5$ \\
\hline 7 & Not known & On & 3 & Small break & 1 & $\mathrm{~S} / \mathrm{N}$ & Drain/cryo/buckle/air & $6 / 36$ & $6 / 12$ & $6 / 9$ \\
\hline 8 & 1 & On & 6 & $\begin{array}{l}\text { Holes in necrotic } \\
\text { retina }{ }^{\star}\end{array}$ & $3^{\star}$ & $\mathrm{I} /$ post & Vitrectomy/laser/gas & $2 / 60$ & $6 / 36$ & $6 / 5$ \\
\hline 9 & 3 & Off & 6 & Small break & 1 & I & Cryo/buckle & $3 / 60$ & $3 / 60$ & $\mathrm{Npl}$ \\
\hline 10 & 0.75 & On & 1 & Large retinal hole* & $2^{\star}$ & $\mathrm{I} / \mathrm{T} /$ post & $\begin{array}{l}\text { Vitrectomy/laser/buckle/gas } \\
\text { Vitrectomy/retinotomy/oil/laser (2) }\end{array}$ & $1 / 60$ & $6 / 60$ & $6 / 6$ \\
\hline 11 & 12 & Off & 4 & Holes in lattice & multiple & $\mathrm{I} / \mathrm{T}$ & Drain/cryo/buckle & $3 / 60$ & $6 / 36$ & $6 / 5$ \\
\hline 12 & Not known & Off & 5 & $\begin{array}{l}\text { Dialysis }+3 \text { small } \\
\text { holes }\end{array}$ & 4 & $\mathrm{I} / \mathrm{T}$ & Drain/cryo/buckle & $6 / 36$ & $6 / 36$ & $6 / 9$ \\
\hline 13 & 6 & Off & 3 & Dialysis & 1 & $\mathrm{~T}$ & Cryo/buckle & $\mathrm{CF}$ & $6 / 12$ & $6 / 5$ \\
\hline 14 & Not known & Off & 10 & Dialysis & 1 & $\mathrm{I} / \mathrm{T}$ & Drain/cryo/buckle & $\mathrm{CF}$ & $6 / 60$ & $6 / 6$ \\
\hline 15 & 0.1 & Off & 5 & Small break & 1 & $\mathrm{I} / \mathrm{T}$ & $\begin{array}{l}\text { Drain/cryo/buckle } \\
\text { Vitrectomy/retinotomy/oil/laser (1) } \\
\text { vitrectomy/peel/oil top up (2) } \\
\text { Vitrectomy/peel/laser/oil (4) } \\
\text { Vitrectomy/retinotomy (6) } \\
\text { Lensectomy/IOL/oil top up (7) } \\
\text { Vitrectomy/peel/retinotomy (9) }\end{array}$ & $\mathrm{CF}$ & PL & PL \\
\hline
\end{tabular}

Mean 2.92 .

*With macula hole.

$\mathrm{I}=$ inferior, $\mathrm{S}=$ superior, $\mathrm{T}=$ temporal, $\mathrm{N}=$ nasal, Post $=>10 \mathrm{~mm}$ behind ora . 
the 864 cases of $R R D$ repair carried out at our unit during the 5 year study period, only 15 $(1.7 \%)$ were in children aged between $0-16$ years.

At least one predisposing aetiological factor was present in $80 \%$ of our group, of which half were trauma. The remainder who had no predisposing factors, all had inferior dialyses presenting as an incidental finding. It would seem that RRD other than dialysis is very unusual in children unless there is some identifiable predisposing aetiology.

It is of note that some $47 \%$ presented as an incidental finding. All these patients had significantly poorer visual acuity in the affected eye, and all had good visual acuity (D 6/9) in their unaffected eye. This demonstrates the lack of symptomatic complaint in children who have unilateral poor vision, and emphasises the need for vigilance during follow up where vision threatening complications may develop in the absence of significant symptoms.

The majority of patients $(80 \%)$ underwent conventional external approach retinal detachment repair. This is because in our study group the majority of patients had peripheral, inferior retinal breaks. Primary vitrectomy was reserved for those cases with posterior tears, not amenable to conventional surgery with buckling. Children tend to develop localised areas of posterior vitreous detachment (PVD) only, with strong areas of vitreoretinal adhesion elsewhere. This makes vitrectomy surgery more difficult in children, and hence where possible an external approach is preferred.

Our overall reattachment success rate of $86.6 \%$ compares favourably with other published series in both adults and children. ${ }^{10}$ However, some $46.6 \%$ had either no visual improvement or worsening of vision, and only $26.6 \%$ achieved vision of better than $6 / 12$. The main cause of this was PVR or macula scarring which occurred in $33 \%$ of the patients, and the three patients requiring reoperations did so as a result of PVR.
Our study is limited by the small numbers of patients involved. Also, although the mean follow up was 14.7 months, two patients only had follow up data available for 3 months (at which time they remained reattached). The relative rarity of RRD among children compared with adults means that numbers will always be small in an audit of a single unit. In addition, since techniques in retinal detachment surgery are rapidly changing and evolving, a longer study period, with increased numbers, may not accurately reflect the results of the most modern surgical approach.

Notwithstanding these limitations, these data provide one unit's experience over a 5 year period, and may help provide a basis for information for patients and their parents when discussing the risks and potential benefits of surgery for retinal detachment in the paediatric population.

Proprietary interest: None.

1 Winslow R, Tasman W. Juvenile rhegmatogenous retinal detachment. Ophthalmology 1978;85:607-18.

2 Scott IU, Flynn HW Jr, Azen SP, et al. Silicone oil in the repair of pediatric complex retinal detachments: a prospective, observational, multicentre study. Ophthalmology 1999;

3 Karel I, Michalickova M. Pars plana vitrectomy in the pediatric population: indications and long-term results. Eur $\mathcal{F}$ Ophthalomol 1999;9:231-7.

4 Ferrone PJ, McCuen BW, de Juan E, et al. The efficacy of silicone oil for complicated retinal detachments in the pediatric population. Arch Ophthalmol 1994;112:773-7.

5 Biedner B, Rothkoff L, Klemperer I. Silicone oil for complicated retinal detachment in the paediatric population. Eur f Ophthalmol 1996;6:451-3.

6 Hinz BJ, de Juan E Jr, Repka MX. Scleral buckling surgery for active stage $4 \mathrm{~A}$ retinopathy of prematurity. Ophthalmolfor active stage 4A retin
ogy 1998;105:1827-30.

7 Ricci B, Santo A, Ricci F, et al. Scleral buckling surgery in stage 4 retinopathy of prematurity. Graefes Arch Clin Exp Stage 4 retinopathy of prematurity. G

8 Haring G, Wiechens B. Long-term results after scleral buckling surgery in uncomplicated juvenile retinal detachment without proliferative vitreoretinopathy. Retina 1998; 18:501-5

9 Sullivan PM, Luff AJ, Aylward GW. Results of primary retinal reattachment surgery: a prospective audit. Eye 1997;11: 869-71.

10 Grizzard WS, Hilton GF, Hammer ME, et al. A multivariate analysis of anatomic success of retinal detachments treated with scleral buckling. Graefes Arch Clin Exp Ophthalmo 